\title{
Cellular Dynamics in Root Formation of Teeth in Rhesus Monkeys
}

\author{
ERNEST B. KENNEY and SIGURD P. RAMFJORD \\ Department of Periodontics, School of Dentistry, University of Michigan, Ann Arbor, \\ Michigan 48104
}

The cellular kinetics around the developing root apex of rhesus monkey teeth were studied using tritiated thymidine. Labeled cells of the epithelial diaphragm did not show migration into the periodontal ligament to become cell rests of Malassez. The periodontal region adjacent to the root apex was a zone of active proliferation of connective tissue cells.

The role of the various cellular components associated with root formation has been controversial since Malassez ${ }^{1}$ and Hertwig ${ }^{2}$ presented their theories.

The advent of isotopes such as tritiated thymidine has made it possible to study cellular turnover and migratory patterns with much greater accuracy than was previously possible. Such technics have been applied to studies of mitotic activity associated with tooth formation, frequently for continuously erupting teeth in small animals. ${ }^{3-9}$ However, the migration pattern of the cells involved in root formation has received little attention.

The purpose of the present study was to investigate the pattern of cell movements associated with root formation in order to gain a better understanding of the role of the various cellular elements in the formation of cementum and dentin at the apex of the growing root.

\section{Materials and Methods}

Four young male rhesus monkeys and a baby monkey were used for this study. The second permanent molars and the permanent lateral incisors were in the process of eruption for the male monkeys; for the 5-dayold baby monkey, the deciduous central in-

This investigation was supported by the Veterans Administration Hospital, Ann Arbor, Mich.

Received for publication July 10, 1968. cisors were erupting. All animals received at the same time of the day $1 \mu \mathrm{c}$ tritiated thymidine/gram of body weight (specific activity 6.7 curies per millimol). Intravenous administration of the thymidine was used for the four male monkeys, and intraperitoneal injection for the baby. The baby and one of the older monkeys were sacrificed one hour after the administration of tritiated thymidine, whereas the remaining three monkeys were killed after two days, seven days, and 12 days, respectively.

Sections for histological studies and radioautographs were prepared according to previously described methods. ${ }^{10}$

Teeth which had penetrated the oral mucosa but had not reached functional occlusal contact were selected for the study (Fig 1). Cell counts were made from the three sections closest to the long axes of the teeth. These groups of sections from four teeth for each of the experimental time periods were studied.

The labeled cells were recorded on graph paper, providing a composite diagram for each of the four experimental time periods after thymidine administration. Epithelial cells were positioned on the composite diagrams by the numerical position of labeled cells compared to the total number of epithelial diaphragm cells. Connective tissue cells were positioned using $\times \mathbf{4 0 0}$ magnification and a $10-\mathrm{mm}$ eyepiece micrometer disk to place labeled cells on a grid. Labeled osteoblasts were also positioned using this grid (Fig 2).

\section{Results}

Epithelial cells.-Epithelial cells were arranged as an epithelial diaphragm composed of one to five layers of cells running from the tip of the developing root apex 


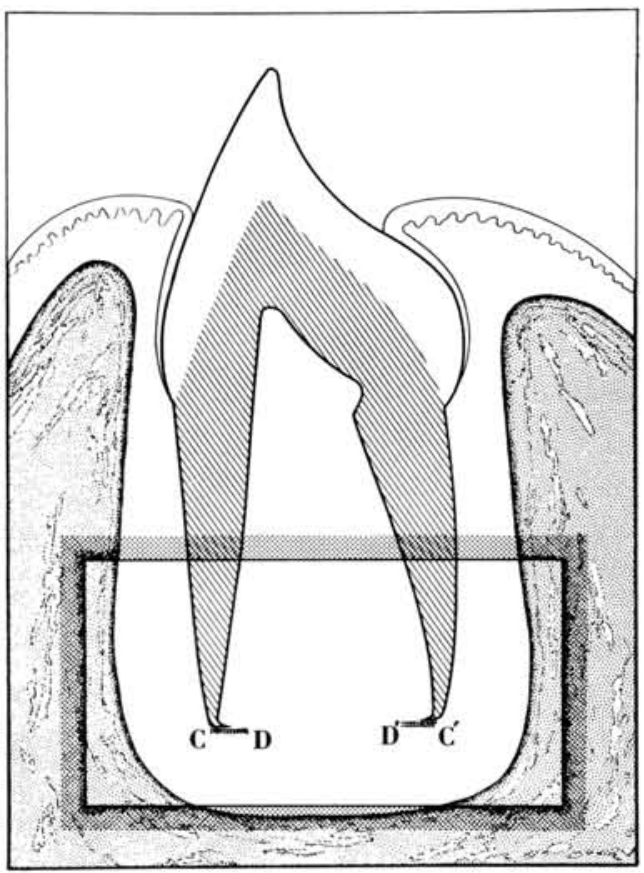

FIG 1.-Diagram of section of teeth. Rectangle shows apical region investigated. $C$ to $D$, and $C^{\prime}$ to $D^{\prime}$, epithelial diaphragm.

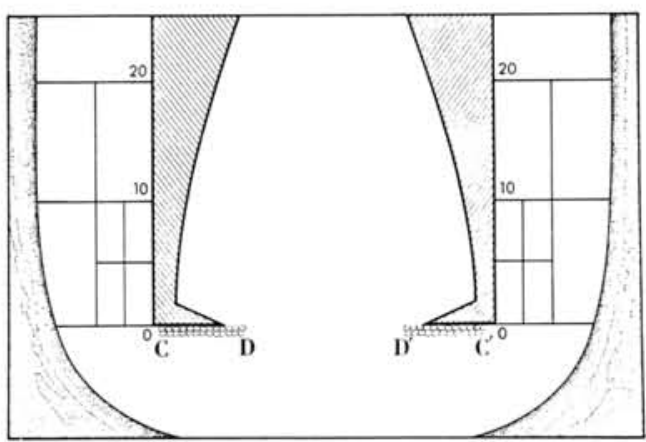

FIG 2.-Diagrammatic enlargement of rectangle in Fig 1. Epithelial cells were positioned on composite diagram by numerical position of labeled cells counted from $C$ to $D$ and $C^{\prime}$ to $D^{\prime}$ compared with total number of epithelial diaphragm cells. Labeled connective tissue cells positioned using the grid 0 to 20 . Labeled osteoblasts between level 0 and 20 were positioned numerically on composite charts.

in toward the future dental pulp. Tritiated thymidine labeled many of the cells of the epithelial diaphragm in sections from all four time periods studied (Fig 3). The

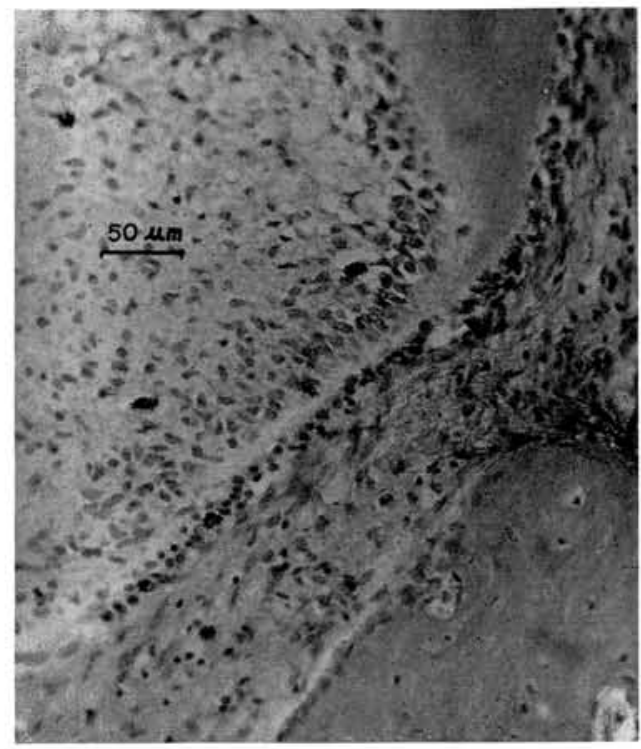

FIG 3.-Labeled cells in epithelial diaphragm at one hour (orig mag $\times 275$ ).

radioactive indexes of this labeling can be seen in Table 1.

TABLE 1

${ }^{3} \mathrm{H}$ Thymidine Radioactive Indexes of Cells of the Epithelial Diaphragm

\begin{tabular}{rccc}
\hline \hline & $\begin{array}{c}\text { Total Cells } \\
\text { Counted }\end{array}$ & $\begin{array}{c}\text { Total Cells } \\
\text { Labeled }\end{array}$ & $\begin{array}{c}\text { Radioactive } \\
\text { Index } \\
\text { Labeled })\end{array}$ \\
\hline 1 hour & 1,270 & 39 & 3.05 \\
2 days & 1,108 & 24 & 2.17 \\
7 days & 712 & 21 & 2.95 \\
12 days & 984 & 23 & 2.34 \\
\hline
\end{tabular}

Labeled epithelial cells were found all along the length of the diaphragm, with no evidence of any definite migration pattern of these cells during the time intervals (Fig 4).

The cells lining the lateral surface of the developing root apexes appeared to be fibroblasts and fibrocytes with no evidence of a lateral epithelial root sheath (Fig 5). Epithelial cells around the root were confined to the epithelial diaphragm; epithelial rests were present only in the more coronal regions of the periodontal ligament.

No labeling of these cell rests of Malassez was seen in any of the sections studied.

Connective tissue cells.-Fibroblasts were labeled throughout the dental sac and 


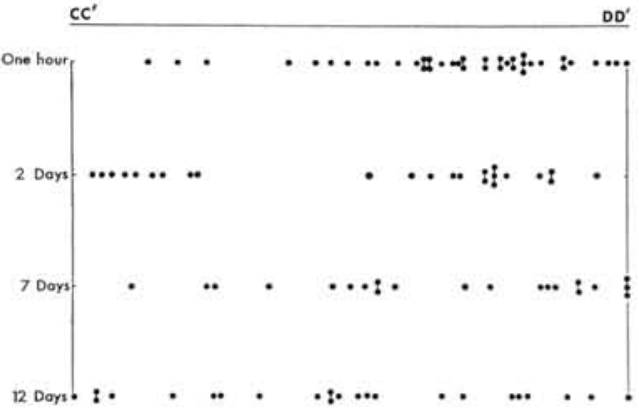

FIG 4.-Composice diagrams with labeled cells of the epithelial diaphragm positioned along the length of the diaphragm. Each point represents one labeled cell.

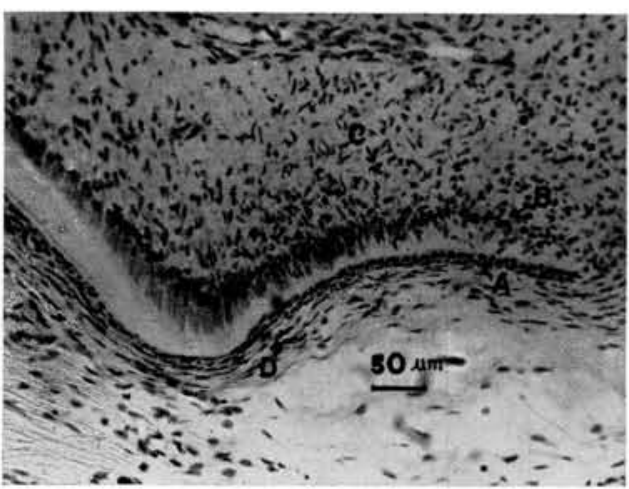

FIG 5.-Root extension with labeled cells of (A) epithelial diaphragm, $(B)$ preodontoblasts, (C) dental papilla, and (D) dental sac, at one hour (orig mag $\times 208$ ).

the developing periodontal ligament around the root apex. Those connective tissue cells immediately apical to the epithelial diaphragm were frequently labeled, as were those cells in the region adjacent to the developing root apex (Fig 6). The composite diagrams show that most of the connective tissue labeling occurred in the immediate vicinity of the root apex, without any pattern of cell multiplication suggestive of any intermediate plexus (Fig 7-10).

Although some connective tissue cells of the dental papilla were labeled, no attempt was made to chart or count them. Preodontoblasts also were frequently labeled; however, in none of the sections had odontoblasts taken up tritiated thymidine.

A tapered amorphous projection from the developing root extended from the apex to the long axis of the tooth. The apical down-

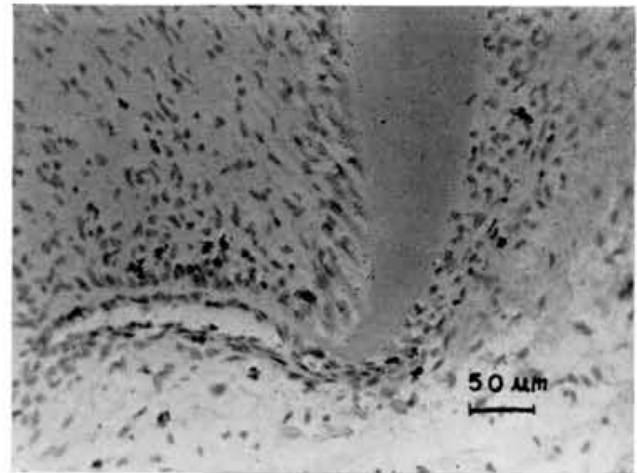

Fig 6.-Labeled connective tissue cells in region of root apex at seven days (orig mag $\times 226)$.

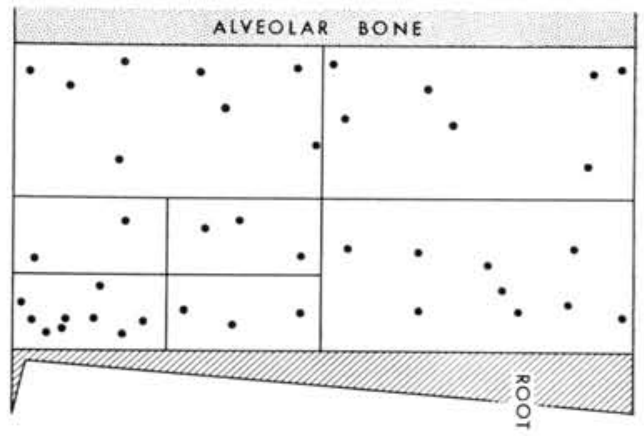

FIG 7.-Composite diagram of labeled connective tissue cells at one hour. Each point represents three labeled cells.

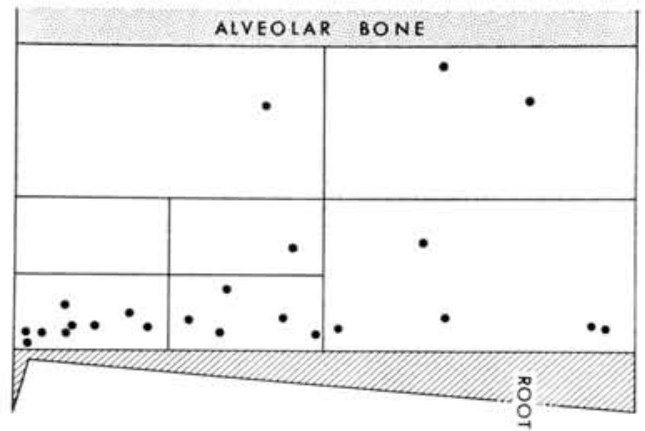

FIG 8.-Composite diagram of labeled connective tissue cells at two days. Each point represents three labeled cells.

ward surface of this extension was covered by the epithelial diaphragm, and preodontoblastic cells of the dental papilla lined the pulpal surface. These cells of the dental 


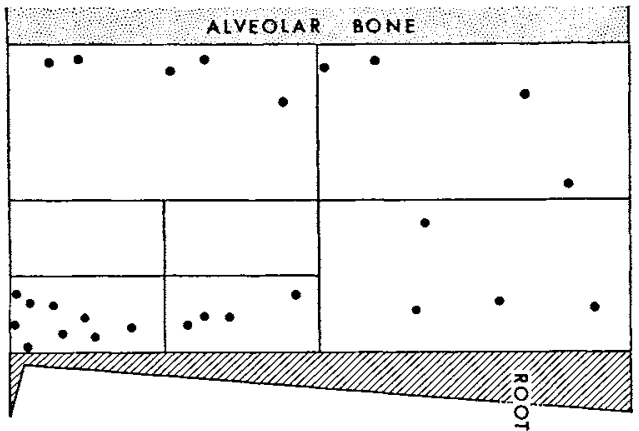

FIG 9.-Composite diagram of labeled connective tissue cells at seven days. Each point represents three labeled cells.

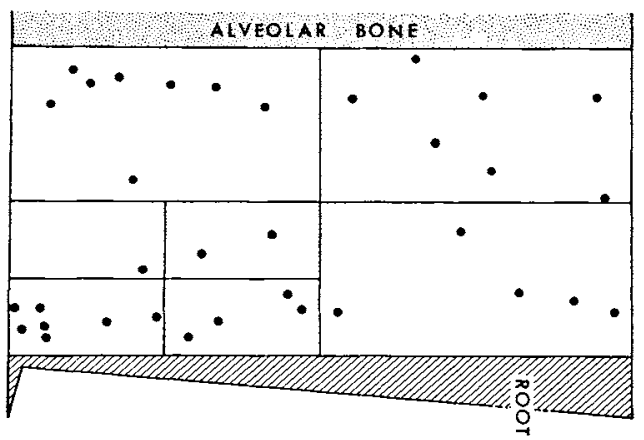

FIG 10.-Composite diagram of labeled connective tissue cells at 12 days. Each point represents three labeled cells.

papilla were lined up along the root extension in progression from undifferentiated mesenchymal cells at the tip to organized odontoblasts at the junction of the extension and the root proper (Fig 5).

CEMENTOBLasts.--Labeled cementoblasts were charted along the entire length of the root and appeared to be randomly positioned. Radioactive indexes appear in Table 2.

Initial formation of cementum occurred coronally to the epithelial diaphragm at the most apical level of calcification of the dentin. Fibroblast-like cells were associated with this initial layer of cementum, and classical cuboidal cementoblasts were not seen until some cementoid material had been laid down.

Osteoblasts. - There was considerable osteoblastic activity in the apical regions, but no organized pattern of osteoblast multiplication was seen. The radioactive indexes
TABLE 2

${ }^{3} \mathrm{H}$ Thymidine Radioactive IndeXes of Osteoblasts in the Region OF the RoOT Apex and of Cementoblasts along the ENTIRE ROOT LENGTH

\begin{tabular}{lccc}
\hline \hline & $\begin{array}{c}\text { Total Cells } \\
\text { Counted }\end{array}$ & $\begin{array}{c}\text { Total Cells } \\
\text { Labeled }\end{array}$ & $\begin{array}{c}\text { Radioactive } \\
\text { Index } \\
\text { (\% Labeled) }\end{array}$ \\
\hline $\begin{array}{l}\text { Osteoblasts } \\
\text { 1 hour }\end{array}$ & 968 & 12 & 1.24 \\
2 days & 810 & 20 & 2.47 \\
7 days & 961 & 17 & 1.77 \\
12 days & 1,306 & 17 & 1.30 \\
Cementoblasts & & & \\
1 hour & 4,254 & 11 & 0.26 \\
2 days & 4,659 & 20 & 0.43 \\
7 days & 6,007 & 20 & 0.33 \\
12 days & 5,246 & 4 & 0.08 \\
\hline
\end{tabular}

for osteoblasts were much higher than the indexes for cementoblasts (Table 2), indicating that osteoblasts were proliferating at a faster rate than were the cementoblasts.

\section{Discussion}

EpITHelial cells.-The demonstration of a significant turnover of cells of the epithelial diaphragm in the rhesus monkeys confirms the previous report of $\mathrm{McHugh}$ and Zander. ${ }^{8}$ Diab and Stallard ${ }^{5}$ described cells labeled with tritiated thymidine in the root sheath of rats and felt that these cells were migrating coronally along the root sheath. In the present study, no discernible migration of labeled epithelial diaphragm cells was detected; nor were epithelial rests present in the apical regions. It therefore seems unlikely that epithelial cells were moving along the epithelial diaphragm into the surrounding connective tissue.

The cell rests of Malassez which were present in the upper portion of the developing periodontal ligament may have been derived from fragmentation of the epithelial root sheath at the initial stages of root development. However, at the period of root development seen in this study, there was no lateral epithelial root sheath. Thus, at least at this stage, the form of the root was not under control of a Hertwig's lateral root sheath.

Connective tissue cells.-The region immediately adjacent to the apex of the root had the highest index of labeling of the developing periodontal ligament. There appeared to be a pattern of migration of connective tissue cells from the dental sac 
(apically to the epithelial diaphragm) into the region immediately lateral to the developing root apex. This pattern of cell migration would explain the almost constant number of labeled cells in the region next to the root apex.

There was no evidence of an intermediate plexus of dividing cells in the apical parts of the periodontal ligament. Previous studies using tritiated proline in erupted mice and hamster teeth have suggested the presence of an intermediate plexus; ${ }^{1-12}$ but Mühlemann et $\mathrm{al}^{13}$ found no evidence of such a plexus when counting mitoses in periodontal ligaments of erupted rat molars. McHugh and $Z_{\text {ander }}{ }^{8}$ studied the entire periodontal ligament in erupting teeth of rhesus monkeys and found the alveolar bone surface and the middle third of the periodontal ligament had more cells labeled with tritiated thymidine than did the corresponding cemental third of the periodontal ligament. The present study provided some quantitation of results only in a small apical area; in tabulating the data, osteoblasts and cementoblasts were considered separately from the other periodontal ligament cells. In this study, the cemental third of the periodontal ligament showed the most labeling.

The cells of the dental papilla were separated from the epithelial diaphragm by the amorphous root extension. Therefore any effect on odontoblastic differentiation exerted by the cells of the epithelial diaphragm would have to be through this root extension.

CEMENTOBLASTS.-.-Initiation of cementum did not appear to be associated with the dissolution of the epithelial covering of the root. Instead, cementogensis occurred coronally to the epithelial diaphragm. This strengthens the suggestion of Diab and Stallard ${ }^{5}$ that cementogenesis is not dependent on the epithelial components around the root apex.

OSTEOBLASTS.-Whereas definite osteoblastic activity was present in the region of the root apex, osteoclasts were not often seen. It seems likely, therefore, that some osteogenic activity was occurring in these regions, causing the apical alveolar bone to be in a process of dynamic spatial rearrangement.

\section{Conclusions}

The epithelial diaphragm together with the root extension may play a role in odontoblastic differentiation, but cementogenesis is apparently not dependent on the epithelial diaphragm. Since the epithelial diaphragm did not appear to contribute to the formation of Malassez epithelial rests, further research is indicated to determine their exact derivation.

There was considerable proliferation of connective tissue cells around the developing root apex; however, the role these cells play in root formation and eruption requires clarification.

Multiplication of osteoblasts occurred around the fundus of the developing teeth, indicating that this is a region of dynamic bone changes which may be related to the eruptive process.

The administration of the isotopes was by Carlos $\mathrm{E}$. Nasileti, and the histologic sections and radioautographs were prepared by Jean I. Simons and Virginia W. Hartog, at the Veterans Administration Hospital, Ann Arbor, Michigan.

\section{References}

1. Malassez, L.: On the Existence of Masses of Epithelium Round the Roots of Adult Teeth in a Normal State, $J$ Brit Dent Assoc 6:370-377, 1885.

2. Hertwig, O.: Archiv für Mikr Anat Bd XI Suppl VII +205, 1874.

3. HWang, W.S.S.; Cronkite, E.P.; and TONNA, E.A.: Cell Proliferation Kinetics of the Internal Enamel Epithelium of Mouse Incisors, J Dent Res 45:350-358, 1966.

4. Stallard, R.E.; Diab, M.A.; and Zander, H.A.: Kinetics of Deoxyribonucleic Acid Synthesis within the Inner Enamel Epithelium, $J$ Dent Res 45:315-322, 1966.

5. Diab, M.A., and Stallard, R.E.: A Study of the Relationship between Epithelial Root Sheath and Root Development, Periodont 3:10-14, 1965.

6. Starkey, W.E.: The Migration and Renewal of Tritium Labeled Cells in the Developing Enamel Organ of Rabbits, Brit Dent J 115:143-153, 1963.

7. Hunt, A.M., and Paynter, K.J.: The Role of Cells of the Stratum Intermedium in the Development of the Guinea Pig Molar. A Study of Cell Differentiation and Migration Using Tritiated Thymidine, Arch Oral Biol 8:65-78, 1963.

8. MCHugh, W.D., and Zander, H.A.: Cell Division in the Periodontium of Developing and Erupted Teeth, Dental Pract 15: 451-457, 1965 . 
9. Chiba, M.: Cellular Proliferation in the Tooth Germ of the Rat Incisor, Arch Oral Biol 10:707-718, 1965.

10. ENGLER, W.O.: RAMFJord, S.P.: and HiNIKER, J.J.: Development of Epithelial Attachment and Gingival Sulcus in Rhesus Monkey, J Periodont 36:44-57, 1965.

11. Anderson, A.: The Protein Matrixes of the Teeth and Periodontium in Hamsters:
A Tritiated Proline Study, $J$ Dent Res 46: 67-78, 1967.

12. Stallard, R.E.: The Utilization of $\mathrm{H}^{3}$ Proline by the Connective Tissue Elements of the Periodontium, Periodont 1:185-188, 1963.

13. MühlemanN, H.R.; Zander, H.A.; and Halberg, F.: Mitotic Activity in the Periodontal Tissues of the Rat Molar, J Dent Res 33:459-467, 1954. 